\title{
Non-native species as conservation priorities: response to Díez-León et al.
}

\author{
Miguel Clavero \\ Estación Biológica de Doñana - CSIC. Avd. Américo Vespucio s/n, 41092 Sevilla, Spain, email: \\ miguelclavero@ebd.csic.es
}

I argue (Clavero 2014) that the conservation efforts devoted in Spain to non-native species (white-clawed crayfish [Austropotamobius italicus] and European mink [Mustela vison]) are an example of shifting baseline syndrome because degraded (i.e., invaded) ecosystems states are now perceived as desirable. The syndrome is further manifested in the generalized rejection of ecologically similar North American species introduced more recently (red swamp [Procambarus clarkii] and signal [Pacifastacus leniusculus] crayfish and American mink [Neovison vison]). Díez-León et al. (2014) believe this reasoning is misleading for two main reasons: lack of evidence of the non-native status of the white-clawed crayfish and European mink and lack of relevance of a species' status as native or nonnative in setting conservation priorities. I considered whether human-mediated introduction constitutes a satisfactory explanation of the presence of the two species in the Iberian Peninsula and whether it makes sense making non-native species conservation priorities.

\section{Native versus non-native}

Biogeographical patterns, distribution dynamics, cultural heritage, and historical evidence related to the white-clawed crayfish support its non-native status in the Iberian Peninsula (Clavero \& Villero 2014). Díez-León et al. ignored most such evidence; their argument relies on genetic studies that they believe provide "strong support" for the native status of the white-clawed crayfish in Spain (e.g., Pedraza-Lara et al. 2010). However, these studies do not provide strong support for their argument. Their claim that the crayfish is native in the Iberian Peninsula is based solely on the species' relatively high genetic diversity and the existence of unique mitochondrial haplotypes. Neither of these features is indicative of native status (Roman \& Darling 2007; Lejeusne et al. 2014). In fact, a closer look at the results of some of the genetic studies lends support to the non-native status of the white-clawed crayfish (e.g. interpreting haplotype networks as in Chapman et al. 2008). 


\section{Non-natives and conservation priorities}

The close relationship between Spanish and Italian white-clawed crayfish is difficult to explain without factoring in human movement of the species, as evidenced, for example, by the fact that Spain and Italy do not share any non-migratory native freshwater fish..

Michaux et al. (2005) favor the hypothesis of a human-mediated origin of the western (i.e., France and Spain) population of the European mink over other possibilities, such as long-distance migration of a few individuals. Contrary to Díez-León et al.’s suggestions, Michaux et al. (2005:2382) state, "present-day populations of western and southeastern Europe cannot have been the refugial populations." It is true that the European mink arrived in Spain from France (where the initial introduction took place) by its own means, but an expanding population of an introduced species does not become automatically native when it crosses a political border. The mink followed the same route into Spain as two other semiaquatic mammals originally introduced to France, the coypu (Myocastor coypus) and the muskrat (Ondatra zibethicus) (Elosegi 2004; Salsamendi et al. 2009). I assume no one considers these species native to Spain.

\section{Setting priorities for conservation}

For Díez-León et al. the native or non-native status "is not a necessary or sufficient basis for the design of conservation policies." They seem to propose that global endangerment of a species is sufficient reason to actively protect and even promote nonnative populations wherever they are. From this perspective, the establishment of new populations of the white-clawed crayfish and European mink in Spain could be considered historical examples of managed relocation (Hoegh-Guldberg et al. 2008). However their maintenance currently depends on large conservation efforts, due to threats to the species (new non-native species) that could not have been forecasted when introductions took place. The eventual inefficiency of these once successful introductions should be taken into account when evaluating the trade-offs of managed relocations (Richardson et al. 2009) because costs (impacts on native biota) accrue in the short term while assumed benefits (creation of new populations) may not be achieved in the long run.

Some authors argue that management of natural systems should judge species by their role in ecosystems, instead of focussing on their origin, because introduced species have no particular tendency to have negative ecosystems effects (Davis et al. 2011). Empirical evidence seems to contradict this statement (Paolucci et al. 2013), but, probably more importantly, nativeness is an objective piece of information that can be used to guide conservation. The definition of nativeness does have weaknesses, such as relying on a negation (the non-intervention of humans in the presence of a species in an area) or being 


\section{Non-natives and conservation priorities}

hindered by the dynamic nature of species ranges (Chew \& Hamilton 2010). In spite of this, nativeness is in most cases a more useful criteria than ecological roles to guide conservation actions and strategies, because determining ecological roles is generally more difficult, context specific, affected by temporal dynamism, expensive, and subjective than judging nativeness. The focus of conservation strategies on native species can have a subjective component (e.g., sense of belonging or attachment to places) (Olden et al. 2005), but is objectively justified by the fact that regional distinctiveness of biotas is a relevant biodiversity component (Olden 2006) and the principle that species should be conserved in the environment (including the biota) they evolved in (e.g., Soule 1985).

Díez-León et al. argue that conservation decisions should be based on "rigorous scientific data", but also that conservation policies should not change following new scientific findings (in the form of knowledge of historical distributions or new phylogenies). They seem to defend the status quo and maintain that changes in the perception of species that concentrate conservation efforts (e.g., by considering them nonnative) could jeopardize current conservation strategies. And, yes, strategies are and should be affected. A determination that the white-clawed crayfish and European mink are not native to Spain should lead to a revision of conservation targets, which are the basis for the development of conservation strategies (Salafsky et al. 2002). This does not mean, and I never claimed, that all five species discussed in Clavero (2014) (the three crayfish and the two mink species) should be "managed as non-native species without further considerations", as interpreted by Díez-León et al. The question is not whether declining non-native species should be subjected to population control or eradication; rather, it is whether non-native species should become first-line conservation priorities (Gippoliti \& Amore 2006). I do not believe a yes answer to this question is impossible or morally unacceptable. Several options are available regarding conservation targets, including (as in the Spanish case) struggling to conserve the remaining populations of introduced species. It is, however, reasonable to question the appropriateness of concentrating conservation efforts on non-native species, not only because this implies a shift in our baseline image of desirable ecosystems, but also because conservation resources would be necessarily rerouted from actions focused on native species (e.g., Botrill et al. 2009).

\section{Acknowledgments}

Comments by M. Delibes and several reviewers improved this work. I had a Ramón y Cajal contract funded by the Spanish Ministry of Science and Innovation 


\section{Non-natives and conservation priorities}

\section{Literature Cited}

Bottrill, M., et al. 2009. Finite conservation funds mean triage is unavoidable. Trends in Ecology \& Evolution 24: 183-184.

Chapman, J. W., A. M. Blakeslee, J. T. Carlton and M. R. Bellinger. 2008. Parsimony dictates a human introduction: on the use of genetic and other data to distinguish between the natural and human-mediated invasion of the European snail Littorina littorea in North America. Biological Invasions 10: 131-133.

Chew, M. K. and A. L. Hamilton. 2010. The rise and fall of biotic nativeness: a historical perspective. Pages 35-47 in D. M. Richardson, editor. Fifty years of invasion ecology: the legacy of Charles Elton. Wiley-Blackwell, West Sussex.

Clavero, M. 2014. Shifting baselines and the conservation of non-native species. Conservation Biology 28: 1434-1436

Clavero, M. and D. Villero. 2014. Historical ecology and invasion biology: long-term distribution changes of introduced freshwater species. BioScience 64: 145-153

Davis, M., et al. 2011. Don't judge species on their origins. Nature 474: 153-54.

Díez-León, M., R. Miranda, A. H. Ariño and D. Galicia. 2014. Setting priorities for existing conservation needs of crayfish and mink. Conservation Biology DOI: $10.1111 /$ cobi.12406.

Elosegi, M. M. 2004. Observación de una rata almizclera, Ondatra żibetbicus (Linnaeus, 1766), en Ezkurra (Navarra). Galemys 16: 63-64

Gippoliti, S. and G. Amori. 2006. Ancient introductions of mammals in the Mediterranean Basin and their implications for conservation. Mammal Review 36: 37-48

Hoegh-Guldberg, O., L. Hughes, S. McIntyre, D. B. Lindenmayer, C. Parmesan, H. P. Possingham and C. D. Thomas. 2008. Assisted colonization and rapid climate change. Science 321: 345-346

Lejeusne, C., A. Saunier, N. Petit, M. Béguer, M. Otani, J. T. Carlton, C. Rico and A. J. Green. 2014. High genetic diversity and absence of founder effects in a worldwide aquatic invader. Scientific Reports 4: art. 5808.

Michaux, J. R., R. Libois, O. J. Hardy, F. Justy, P. Fournier, A. Kranz, M. Cabria, A. Davison, and R. Rosoux. 2005. Conservation genetics and population history of the threatened European mink Mustela lutreola, with an emphasis on the west European population. Molecular Ecology 14: 2373-2388.

Olden, J. D. 2006. Biotic homogenization: a new research agenda for conservation biogeography. Journal of Biogeography 33: 2027-2039. 


\section{Non-natives and conservation priorities}

Olden, J. D., M. E. Douglas and M. R. Douglas. 2005. The human dimensions of biotic homogenization. Conservation Biology 19: 2036-2038.

Paolucci, E. M., H. J. MacIsaac, and A. Ricciardi. 2013. Origin matters: alien consumers inflict greater damage on prey populations than do native consumers. Diversity and Distributions 19: 988-995

Pedraza-Lara, C., F. Alda, S., Carranza and I. Doadrio. 2010. Mitochondrial DNA structure of the Iberian populations of the white-clawed crayfish, Austropotamobius italicus italicus (Faxon, 1914). Molecular Phylogenetics and Evolution 57: 327-342

Richardson, D. M., et al. 2009. Multidimensional evaluation of managed relocation. Proceedings of the National Academy of Sciences USA 106: 9721- 9724

Roman, J. and J. A. Darling. 2007. Paradox lost: genetic diversity and the success of aquatic invasions. Trends in Ecology and Evolution 22: 454-464.

Salafsky, N., R. Margoluis, K. H. Redford and J. G. Robinson. 2002. Improving the practice of conservation: a conceptual framework and research agenda for conservation science. Conservation Biology 16: 1469-1479.

Salsamendi, E., L. Latierro and J. O'Brien. 2009. Current distribution of the coypu (Myocastor coypus) in the Basque autonomous community, Northern Iberian Peninsula. Hystrix 20: 155-160.

Soulé, M. E. 1985. What is conservation biology? BioScience 35: 727-734. 